\title{
RELATIONSHIP BETWEEN TACTICAL BEHAVIOR AND AFFECTIVE DECISION-MAKING IN U-17 YOUTH SOCCER PLAYERS
}

doi: 10.2478/humo-2014-0009

\author{
RODRIGO SANTOS $^{1 *}$, MAICKEL BACH PADILHA ${ }^{1,2}$, ISRAEL TEOLDO $^{1}$ \\ ${ }^{1}$ Centre of Research and Studies in Soccer, Universidade Federal de Viçosa, Brazil \\ ${ }^{2}$ Faculty of Sport, University of Porto, Porto, Portugal
}

\begin{abstract}
Purpose. The aim of this article was to analyze the relationship between tactical behavior and affective decision making of U-17 youth soccer players. Methods. The sample was comprised of 154 participants meeting the study inclusion criteria. Players played 4-min games on four-person teams (including goalkeeper) on a small-sided soccer field. The System of Tactical Assessment in Soccer (FUT-SAT) was used to determine the defensive tactical actions performed by players according to five different tactical principles. A total of 6140 defensive tactical actions were recorded. Their affective decision-making was measured by a computerized card task, the Iowa Gambling Task (IGT). Results. Significant negative correlation was found between players' learning curve and the incidence of actions based on the principle of concentration. Less impulsive players presented a lower incidence of actions tied with the principle of concentration in comparison with more impulsive players. Conclusions. The findings suggest that, in the defensive phase, players who are less impulsive decision makers may benefit from more secure and stable defensive styles.
\end{abstract}

Key words: soccer, tactical behavior, affective decision-making

\section{Introduction}

The study of team sports dynamics through the observation of players' and teams' behavior patterns is longestablished, having emerged concurrently with the demands of professional athleticism [1]. Soccer is a team sport in which unusual task situations are recurrent, where tactical behavior can be defined as a series of actions performed by players in order to contend with match situations using the most suitable means possible under the constraints of time, space, and task [2, 3]. As such, the analysis of tactical behavior in sports should not solely be based on a concrete action performed in isolation but rather on comprehensive (individual and collective) tactical actions that include all the typical characteristics of isolated actions $[4,5]$.

In this respect, studies have been conducted in recent years to analyze tactical behavior in soccer with the purpose of determining to what extent this aspect might be influenced by other variables. Some researches aimed to examine the association between tactical behavior and contextual variables (i.e. match location, playing position, positional demands, and match status) and verified that players' behavior is likely to be affected by these constraints to various extents [6-9]. Other authors addressed the subject by investigating the influence of relative age effect (RAE) and changes in playing area, finding the role of RAE to be rather minor while the increase or decrease of field size demonstrated that tactical behavior patterns might undergo modification according to spa-

\footnotetext{
* Corresponding author.
}

tial constraints $[10,11]$. However, few studies in the literature have attempted to analyze tactical behavior in soccer from a cognitive perspective or tried to find correlations between these two variables [12].

The significance of cognition in the tactical context of soccer is readily apparent, as authors have already highlighted the relevance of studying perceptual and motor structures in order to understand central cognitive processes such as decision-making [13-16]. Decision making can be defined as a process influenced by marker signals that have evolved from bio-regulatory processes, especially those expressed via emotions and feelings, which in turn are engendered by the body in anticipation of upcoming events [17]. In soccer, decision making is regarded as being an attribute of 'game intelligence', which is a factor that discriminates successful and less successful players due to its vital role in selecting and executing actions that are more suitable and more likely to succeed in a particular scenario [18]. Naturally, various perceptual-cognitive patterns are often observed, as players differ from each other in terms of perception, anticipation and, more noticeably, in terms of decision making [19]. It is reasonable to assume that examination of the way players make decisions might provide coaches with more information about the sort of tactical behaviors they could expect from players during a specific match scenario or, particularly at youth levels, how they can develop players' decision-making skills to perform better in later competitive events.

From the age of 5 up to 17, players are still developing various coordination abilities that are crucial for performance in team ball games. However, from 15 to 17 years of age, body coordination and agility, whose de- 
velopment occurs more rapidly than any other maturation and growth processes during this age interval, are nearly fully developed. This suggests that evaluating tactical actions at this age might better reflect how such players will behave in tactical terms when playing at higher competitive levels [20,21].

Thus, in order to further existing knowledge about affective decision-making and how it could underlie players' behavior patterns, the aim of this study was to analyze the relationships between tactical behavior and affective decision making of U-17 youth soccer players.

\section{Material and methods}

\section{Sample and participant selection}

This study was approved by the Research Ethics Committee (133/2012) of Universidade Federal de Viçosa, Brazil and all procedures were in accordance with the standards of the Brazilian National Health Board (466/2012) and Declaration of Helsinki (2008).

Sample inclusion criteria required subjects to be engaged in a systematic training program and belong to a soccer club that participated in tournaments on a regular basis. Soccer club representatives and coaches of U-17 youth teams were contacted and provided with an overview of the study's purpose and procedures. Clubs willing to participate signed a Statement of Authorization, granting permission for their players meeting the study's requirements to participate as well as to the researchers to utilize the clubs' facilities for testing purposes. Parents or guardians of the players also provided written informed consent. In total, $154 \mathrm{U}-17$ youth male soccer players were recruited.

\section{Instrumentation and procedures}

An assessment of the defensive tactical actions performed by players with and without possession of the ball was performed with the System of Tactical Assessment in Soccer (FUT-SAT), developed and validated by Teoldo et al. [22]. This assessment is based on ten core tactical principles in the game of soccer, five offensive principles - (i) Penetration, (ii) Offensive Coverage, (iii) Width and Length, (iv) Depth Mobility, and (v) Offensive Unity - and five defensive principles - (vi) Delay, (vii) Defensive Coverage, (viii) Balance, (ix) Concentration, and (x) Defensive Unity. Actions such as throwins, free kicks, corner-kicks, as well as those in which did not cover any of the above defensive tactical principles were not included in analysis.

In-game tactical actions were assessed through filming the participants playing small-sided soccer games. The playing field was $36 \mathrm{~m}$ long by $27 \mathrm{~m}$ wide with a $6 \mathrm{~m}$ wide by 2 meters tall goal post placed at each end of the field. Players were distributed into teams in a ' $G K+3$ ' arrangement (goalkeeper +3 outfield players) and played against each other. Each game lasted $4 \mathrm{~min}$. Before starting the test, all players were properly informed about the research procedures and objectives and provided with a 30-second familiarization session. Players were asked to play according to the rules of association soccer except for the offside law. No feedback was provided to the players during the tests.

To record the field tests, a Sony HDR-XR100 digital camera (SONY, Japan) was placed diagonally to the goal line and sidelines. The players wore vests with distinct colors and numbers in order to be identified for later video analysis. Video footage was then processed and analyzed using Soccer Analyser software (Eduardo Valgôde, Portugal). In total, 6140 defensive tactical actions were identified.

The second instrument in this study was the Iowa Gambling Task (IGT) developed by Bechara et al. [23] and transculturally adapted to Brazilian Portuguese by Malloy-Diniz et al. [24]. This instrument is a computerized test that assesses the decision-making process by tasks connected with impulsivity due to a lack of planning [25]. It factors several aspects of decision making, including uncertainty, risk, and evaluation of reward and punishment. In this game-shaped test, four decks (labeled A, $\mathrm{B}, \mathrm{C}$, and D) of cards are shown to the participant on a computer screen. At the start, the participant receives a loan of 2000 credits in 'play money' in order to begin playing. He must choose one card at a time from any of the decks. The card can provide a monetary win or loss of different amounts (reward or punishment). Two of the decks (A and B) produce high immediate gains. However, in the long run, these two decks cause the player to lose more money than they win and are therefore considered to be the disadvantageous decks. The other two decks (C and $\mathrm{D})$ are considered advantageous, as they result in smaller gains but yield more money than is lost in the long run.

The rules of the game, however, are not disclosed to the participants; they are required to ascertain how the game works and what the most advantageous strategy is. To the participants, the objective of the game was described to win as much 'play money' as possible. The game ends when the participant chooses the hundredth card. The test was performed on a laptop computer, located in a quiet place free of loud noises, environmental stress, and external distractions that might disturb the subjects while performing the test.

\section{Statistical and reliability analyses}

Net IGT scores, based on each trial of 100 cards, were calculated by subtracting the number of disadvantageous choices (from decks A and B) from the number of advantageous choices (from decks $\mathrm{C}$ and $\mathrm{D}$ ). The global net IGT score was calculated by applying the same formula to a total of 100 trials. In order to examine the correlation between affective decision making and tac- 
tical behavior, we calculated the players' learning curve during the IGT task using descriptive analysis (means and standard deviation) on the scores from each trial. Descriptive statistics (means and standard deviations) for the defensive tactical principles were also calculated. The Kolmogorov-Smirnov test was performed to check the distribution of the data. Spearman's rankorder correlation test was applied to see if any relationships existed between the variables (significance level set at $p<0.05)$. Analyses were performed using SPSS for Windows 20.0 (IBM, USA).

Test-retest reliability of determining tactical actions according to the FUT-SAT was assessed by Cohen's kappa after respecting a three-week interval for reanalysis, thus avoiding the effects of task familiarity [26]. Three observers participated in the procedure. A reassessment of 1812 tactical actions or $29.5 \%$ of the total sample was performed, superior to the minimum value $(10 \%)$ indicated by the literature for this procedure [27]. Intraobserver reliability kappa values were between 0.888 $(\mathrm{SE}=0.007)$ and $0.985(\mathrm{SE}=0.003)$. Inter-observer reliability was found to be between $0.810(\mathrm{SE}=0.023)$ and 0.989 ( $\mathrm{SE}=0.011)$. These values are classified as 'almost perfect' (0.81-1) by the literature [28].

\section{Results}

Mean values revealed that players performed on average $36.55 \pm 8.12$ defensive tactical actions. The mean number of actions of Defensive Unity $(13.37 \pm 5.32)$ performed by players proved to be higher in comparison with the other principles. In contrast, Defensive Coverage $(2.39 \pm 1.91)$ presented lower mean values than all other defensive principles (Tab. 1).

Although correlation analyses did not reveal significant correlations between the IGT results and the incidence of most of the defensive tactical principles (Tab. 2), the principle of concentration presented a significant moderate negative correlation ( $\mathrm{rho}=-0.313, p<0.01$ ). Such a result suggests that increased IGT values promote a decreased incidence of actions of concentration. Despite the results not being significant $(p=0.094)$, the principle of balance showed a weak positive correlation (rho $=0.135)$ with the IGT results.

Table 1. Absolute incidence and means $(S D)$ for players of defensive tactical actions according to principle

\begin{tabular}{lrr}
\hline Defensive Tactical Principle & $n$ & M (SD) \\
\hline Delay & 1146 & $6.82(3.35)$ \\
Defensive Coverage & 402 & $2.39(1.91)$ \\
Balance & 1506 & $8.96(4.18)$ \\
Concentration & 840 & $5.00(3.25)$ \\
Defensive Unity & 2246 & $13.37(5.32)$ \\
Total & 6140 & $36.55(8.12)$ \\
\hline
\end{tabular}

Table 2. Coefficients of correlation (rho) and significance levels of IGT and defensive tactical principles

\begin{tabular}{|c|c|c|c|c|c|c|}
\hline & & \multicolumn{5}{|c|}{ Defensive Tactical Principles } \\
\hline & & $\frac{\vec{\pi}}{\stackrel{\Xi}{\Xi}}$ & 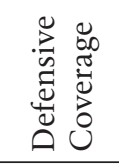 & 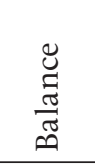 & 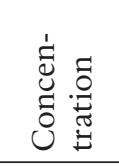 & 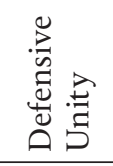 \\
\hline \multirow{2}{*}{ IGT } & rho & -0.041 & -0.026 & 0.135 & -0.313 & -0.002 \\
\hline & $p$ & 0.618 & 0.749 & 0.094 & $<0.001$ & 0.985 \\
\hline
\end{tabular}

Significant moderate negative correlation

(rho $<-0.3, p<0.05)$ is in boldface

\section{Discussion}

The role of cognition in soccer, particularly in the tactical context, is recognized as a crucial subject by the current literature. Despite such a widely held notion, there are few studies, to the authors' best knowledge, that have examined the function of certain cognitive processes for specific behaviors within the dynamics of the game. Aiming to broaden existing knowledge on this subject, we analyzed the relationship between tactical behavior and the affective decision making of U-17 youth soccer players.

Results revealed that players' affective decision making and the incidence of most of the tactical principles were not significantly correlated. Conversely, we found that players' learning curves presented significant moderate negative correlations with the incidence of actions tied with the principle of concentration, implying that players who performed a lower number of actions based on the principle concentration were those whose decisions were predominantly based on planning rather than impulsiveness [17].

According to Worthington [29], one of the main tasks of playing as a defender in soccer is restricting the 'working space' that attackers try to create, an action of opposition which is referred to by the author as the principle of concentration. This principle is based on defensive players' movements toward a zone on the field that, at a given moment, poses a high risk of being taken advantage of by the opposing team to score a goal, with the aim of increasing defensive protection, reducing the space available for attacking opponents to progress, and, consequently, facilitating ball recovery [30, 31].

Based on the findings of the present study and the concepts on which the principle of concentration is founded upon, we assume that players in the defensive phase who are more impulsive decision makers are more likely to position themselves closer to the center of play, thus limiting the working space of the attacker with the ball and denying him a clear view of the goal [29].

Conversely, subjects who presented IGT learning curves indicating decisions based on planning did not demon- 
strate the same behavior pattern. The correlation between planned decision making and the principle of balance, despite not being statistically significant, suggests that players with such a characteristic tend to play laterally in relation to the center of play, especially if taking into account that this tactical principle is based on actions of blocking the space of opposing attacking players (who are not in possession of the ball) and slowing down the pace of the opponent's attack [31, 32].

These interpretations may have implications in the tactical context, especially in terms of visual cues, as more impulsive players may use the ball more often as a reference point when not in possession of the ball, while those less impulsive may tend to base their positioning during the defensive phase on the movements and actions of their opponents. This could be an indication that the role of different affective decision-making patterns may be advantageous depending on the kind of behavior that coaches expect from their defenders. Those coaches who choose to play more aggressive defending styles, exerting high pressure on an attacker in possession of the ball, could benefit from more impulsive players, while coaches who prefer a more conservative style, favoring security over speed and intensity [33], may find less impulsive decision-making players a more suitable choice.

\section{Conclusions}

In summary, affective decision making was negatively correlated with the incidence of the principle of concentration, allowing us to infer that players who display more planned decision making could be better at playing more conservative defending styles, while those who present results that indicate a more impulsive decisionmaking style may be better suited to more aggressive approaches in defense. The main contribution of our study to the current literature relies on the importance of cognition in tactical behavior and therefore on the need to map players' cognitive characteristics, such as decision-making, so as to estimate the behaviors they might display in real match situations.

\section{Acknowledgements}

This study was funded by the State Department of Sport and Youth of Minas Gerais (SEEJ-MG) through the State Act of Incentive to Sports, by the Minas Gerais State Research Foundation (FAPEMIG), the Coordination of Improvement of Higher Level Personnel (CAPES), the National Council for Scientific and Technological Development (CNPq), the Arthur Bernardes Foundation (FUNARBE), the Dean's Office for Graduate and Research Studies, and the Center of Life and Health Sciences at Universidade Federal de Viçosa, Brazil.

\section{References}

1. Garganta J., Performance analysis in team games. Review on match analysis [in Portuguese]. Rev Port Cien Desp, 2001, 1 (1), 57-64.
2. Boulogne G., Game organization - tactics/game plan [in French]. Rev EPS, 1972, 117, 52-55.

3. Duda H., Visual helping instructing of games tactics according to the principles of forceful operations [in Polish]. Annales, 2005, LX, Suppl. XVI (86), 395-399.

4. Mahlo F., Tactical action in play [in French]. Vigot Freres, Paris 1969, 244.

5. Garganta J., Tactical modelling in soccer - a study on the attacking phase in top level teams [unpublished Ph.D. thesis]. Porto, Portugal: University of Porto; 1997.

6. Lago-Peñas C., The influence of match location, quality of opposition, and match status on possession strategies in professional association football. J Sports Sci, 2009, 27 (13), 1463-1469, doi: 10.1080/02640410903131681.

7. Taylor J.B., Mellalieu S.D., James N., Behavioural comparisons of positional demands in professional soccer. Int J Perform Anal Sport, 2004, 4 (1), 81-97.

8. Taylor J.B., Mellalieu S.D., James N., Shearer D.A., The influence of match location, quality of opposition and match status on technical performance in professional association football. J Sports Sci, 2008, 26 (9), 885-895, doi: 10.1080/02640410701836887.

9. Dellal A., Wong D.P., Moalla W., Chamari K., Physical and technical activity of soccer players in the French First League - with special reference to their playing position. Int Sportmed J FIMS, 2010, 11 (2), 278-290.

10. Teoldo I., Garganta J., Greco P.J., Mesquita I., Seabra A., Influence of Relative Age Effects and Quality of Tactical Behaviour in the Performance of Youth Soccer Players. Int J Perform Anal Sport, 2010, 10 (2), 82-97.

11. Dellal A., Owen A., Wong D.P., Krustrup P., van Exsel M., Mallo J., Technical and physical demands of small vs. large sided games in relation to playing position in elite soccer. Hum Mov Sci, 2012, 31 (4), 957-969, doi: 10.1016/ j.humov.2011.08.013.

12. Araújo D., Davids K., Hristovski R., The ecological dynamics of decision making in sport. Psychol Sport Exerc, 2006, 7 (6), 653-676, doi: 10.1016/j.psychsport.2006.07.002.

13. Williams A.M., Davids K., Burwitz L., Williams J., Cognitive knowledge and soccer performance. Percept Motor Skills, 1993,76(2), 579-593, doi: 10.2466/pms.1993.76.2.579.

14. Bar-Eli M., Plessner H., Raab M. Judgement, decision making and success in sport. Wiley-Blackwell, Oxford, 2011.

15. Roca A., Williams A.M., Ford P.R., Capturing and testing perceptual-cognitive expertise: A comparison of stationary and movement response methods. Behav Res Methods, 2014, 46 (1), 173-177, doi: 10.3758/s13428-013-0359-5.

16. Duda H., Cognitive support in teaching football techniques. Biomed Hum Kinetics, 2009, 1 (1), 26-30, doi: 10.2478/ v10101-009-0008-8.

17. Bechara A., The role of emotion in decision-making: Evidence from neurological patients with orbitofrontal damage. Brain Cogn, 2004, 55 (1), 30-40, doi: 10.1016/j. bandc.2003.04.001.

18. Williams A.M., Ford P.R., 'Game intelligence': anticipation and decision making. In: Williams A.M. (ed.), Science and soccer: developing elite performers, 3ed. Routledge, Oxon, 2013, 105-121.

19. Roca A., Ford P.R., McRobert A.P., Williams A.M., Perceptual-Cognitive Skills and Their Interaction as a Function of Task Constraints in Soccer. J Sport Exerc Psychol, 2013, 35 (2), 144-155.

20. Memmert D., Roth K., The effects of non-specific and 


\section{HUMAN MOVEMENT}

R. Santos, M.B. Padilha, I. Teoldo, Tactical behavior and decision-making

specific concepts on tactical creativity in team ball sports. J Sport Sci, 2007, 25 (12), 1423-1432, doi: 10.1080/0264 0410601129755.

21. Kröger C., Roth K., Ball School: An ABC game for beginners [in German]. Hofmann, Schorndorf 1999.

22. Teoldo I., Garganta J., Greco P.J., Mesquita I., Maia J., System of tactical assessment in Soccer (FUT-SAT): Development and preliminary validation. Motri, 2011, 7 (1), 69-84, doi: 10.6063/motricidade.7(1).121.

23. Bechara A., Damasio H., Tranel D., Anderson S.W., Dissociation Of Working Memory from Decision Making within the Human Prefrontal Cortex. J Neurosci, 1998, 18 (1), 428-437, doi: 0270-6474/97/180428-10\$05.00/0.

24. Malloy-Diniz L.F., Leite W.B., Moraes P.H.P., Correa H., Bechara A., Fuentes D., Brazilian Portuguese version of the Iowa Gambling Task: transcultural adaptation and discriminant validity. Rev Bras Psiquiatr, 2008, 30 (2), 144-148.

25. Moeller F.G., Barratt E.S., Dougherty D.M., Schmitz J.M., Swann A.C., Psychiatric Aspects of Impulsivity. Am J Psychiatry, 2001, 158 (11), 1783-1793, doi: 10.1176/appi. ajp.158.11.1783.

26. Robinson G., O’Donoghue P., A weighted kappa statistic for reliability testing in performance analysis of sport. Int J Perform Anal Sport, 2007, 7 (1), 12-19.

27. Tabachnick B., Fidell L., Using Multivariate Statistics: International Edition. 6 ed. Pearson Education, London 2012.

28. Landis R., Koch G.G., The Measurement of Observer Agreement for Categorical Data. Biometrics, 1977, 33 (1), 159-174.

29. Worthington E., Learning \& Teaching Soccer Skills. Wilshire Book Company, North Hollywood 1974.

30. Bangsbo J., Peitersen B. Defensive Soccer Tactics: How to stop players and teams from scoring. Human Kinetics, Champaign 2001.

31. Teoldo I., Garganta J., Greco P.J., Mesquita I., Tactical Principles of Soccer Game: concepts and application in Portuguese. Motriz, 2009, 15 (3), 657-668.

32. Garganta J., Pinto J., Teaching soccer [in Portuguese]. In: Graça A., Oliveira J. (eds.), O ensino dos jogos desportivos. CEJD - FCDEF-UP, Porto 1994, 97-137.

33. Szwarc A., The Efficiency Model of Soccer Player's Actions in Cooperation with Other Team Players at the FIFA World Cup. Hum Mov, 2008, 9 (1), 56-61, doi: 10.2478/ v10038-008-0002-y.

Paper received by the Editors: November 28, 2013

Paper accepted for publication: April 4, 2014

\section{Correspondence address}

Rodrigo Santos

Centre of Research and Studies in Soccer

Universidade Federal de Viçosa, Brazil

Departamento de Educação Física

Av. P. H. Rolfs, S/N

Campus Universitário

Post Code: 36.570-000, Viçosa, Brazil

e-mail: mirandamonteiro@globo.com 